
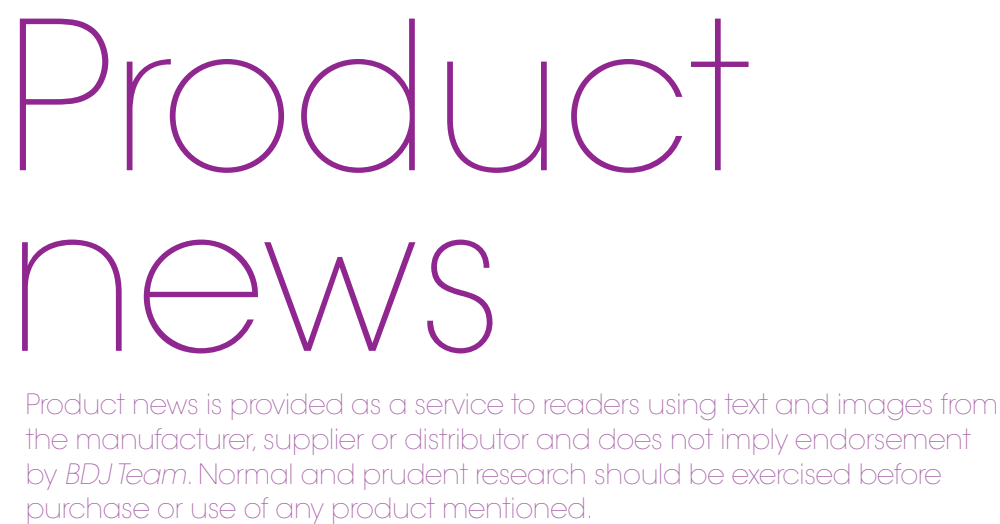

purchase or use of any product mentioned.

\title{
IT'S BACK, AND BETTER THAN EVER
}

This October Dental Showcase returns to London's ExCeL Arena for what will be the industry's best show to date. The logo for this year's event features the famous London Underground, and just as the tube gives London the mobility it needs to give it the edge, Dental Showcase will provide you with the knowledge and insight you need to keep abreast.

The lecture programme at this year's Dental Update Theatre, chaired by Professor Trevor Burke, will cover various topics, with leading academics exploring the latest research and techniques. Dental Update is synonymous with pragmatic education, so you can be sure that what you learn will be relevant to what you practice, day-to-day in your surgery.

Running concurrently with these lectures

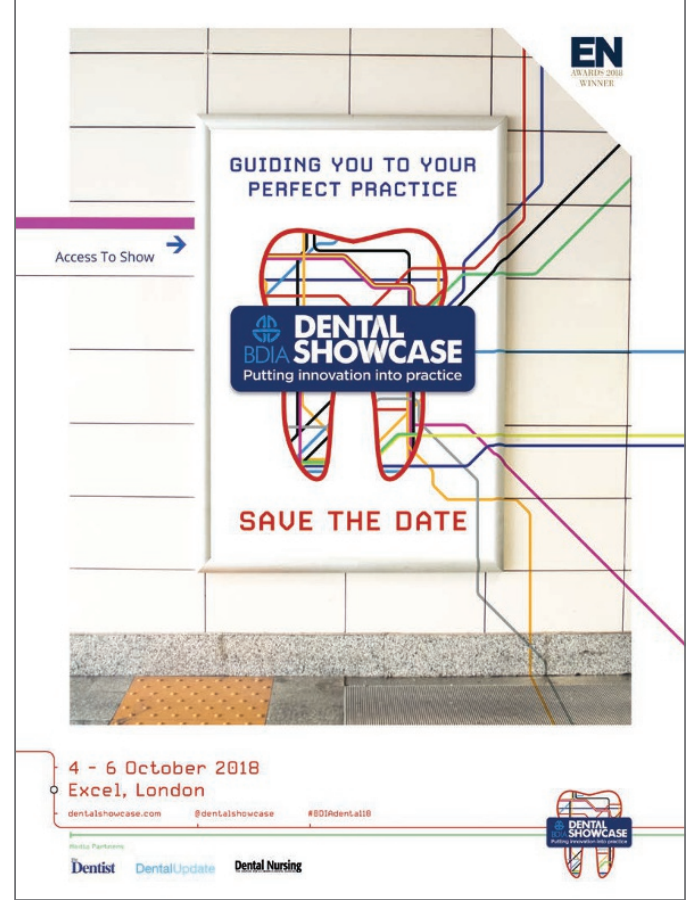

will be live demonstrations in the new Digital Practice Theatre. The application of technology is core to these lectures, and as its moniker suggests, this event will utilise revolutionary new technology, introducing an interactive element to the live demonstrations taking place each morning It's 'wet fingered' dentistry by proxy! The afternoon sessions will give you a look into 'tomorrow's world' with discussions and reviews of the latest technology accessible to dentistry. Pioneers and practitioners will talk you through its evolution and application.

If you want to get 'up close and personal' with those influencing government policy then you won't get a better opportunity than hearing Sara Hurley, Chief Dental Officer (CDO) for England, talking each morning about the development and provision of dental services. The Thursday morning session will be available to dental societies only, but Friday and Saturday are open to all on a first come, first served basis. It is anticipated that these briefings will engender much debate which can be continued at the CDO Zone, where panel discussions will run throughout the three days.

Aside from the lectures, the main attraction for many visitors is to peruse the latest trade innovations under the convenience of a single roof. There will be over 350 exhibitors at this year's Show, many of them choosing to launch new products at the event. If you like to 'try before you buy', and be sure you've thoroughly researched all possibilities, this is your ideal opportunity.

To register, or for more information, visit dentalshowcase.com.

\section{WEBINAR HIGHLIGHTS THE IMPACT OF MODERN DIETS AND LIFESTYLE ONTEETH}

GSK are inviting dental professionals to view an online recording of their recent panel webinar on the topic of enamel wear with a particular focus on younger people and practical advice for this category. The panel was chaired by Dr Rupert Austin (specialist in prosthodontics at King's College London Dental Institute) and he was joined by Dr Manrina Rhoda (cosmetic dental surgeon), Ali Lowe (dental hygienist) and Amit Rai (general dental practitioner).

To access the full webinar footage and gain one hour of verifiable CPD visit https://digital.vevent.com/rt/ gskpronamel $\sim$ webinar and register to view.

A desire for healthy lifestyles was identified as a potential reason for the increase in levels of tooth wear amongst younger patients. Habits including drinking hot water with lemon or snacking on fruit, vegetables and juices can all play a part. It was also highlighted that the stresses of modern life have led to increased signs of bruxism and tooth grinding in practice.

As part of the panel discussion, the group consider and discuss methods to measure and monitor tooth wear in practice, using sites of tooth wear as clues to sources of acid and useful resources available for access. 